\title{
Discussion
}

\section{Chairman: Professor Desmond PoNd}

(The London Hospital)

Mrs AnNe Cohn (Central Middlesex Hospital): I have spent a lot of time in the treatment of frigid and non-consummation patients. I do not have the advantage of medical training so this is a question really to do with this. I do not think you mentioned whether you have found that medication, such as the birth control pill, and medication for mental illness such as mild depression, has any part to play in the patient who says that sex does not frighten, does not put her off, it just means absolutely nothing.

DR I. D. Chisholm: If a patient is depressed then they will have some loss of interest in sexual matters, and if that is the cause of the trouble you have to relieve the depression. If you are seeing the patient for non-consummation it is unlikely to be an important factor in the situation. I did not lay any stress on these medical conditions causing this. I think they do come into it, but if you have a patient who has had difficulties in consummation you help them to consummate. In my experience it is not uncommon to have mild psychiatric disturbances following consummation of the marriage. An anxious woman may get more anxious for a while, an obsessional woman, more obsessional, etc. You have to treat that. With regard to oral contraceptives, I think this does come into the picture but in the sense that a woman who has difficulty in consummating her marriage needs to have quite a period to establish normal sexual relations, and if she becomes pregnant too soon the pattern is interrupted and she may then have a recurrence of all her fears and difficulties. I would argue strongly for allowing such women to have time to establish normal sexual relations before they become pregnant.

Dr I. M. Marks (Maudsley Hospital): I would like to know how you treat late ejaculations and impotence, and secondly, have you encountered any cases complaining of emissions without erection? If so, what was the cause and what was the treatment?

DR A. J. CoOper: I think the treatment of the first condition is almost identical to that of impotence. There is no difference in fact in my experience. Indeed some patients present with impotence on some occasions. In treating impotence you may actually aid it sufficiently to get a good erection, then you find he has delayed or absent ejaculation. The thing which interests me very much about this is why these people can still have nocturnal emissions when they cannot in fact have emissions with masturbation, during coitus or in fact with any conscious experience. I do not know the answer. I think the treatment is exactly the same, in fact based on the provision of the best stimulation which is available.

The second condition, of course, late ejaculation without erection, I have never seen. I would doubt it is possible. I think one has negative accounts in the same way as you get some men who say 'I don't have an orgasm but I ejaculate'. If it does happen one can postulate physiological mechanisms but I don't know of psychological ones.
DR R. J. BARNes (Gloucester): How often is impotence a presenting symptom of marital breakdown?

DR COOPER : I could not in fact say. Masters \& Johnson refer to sexual inadequacy as occurring in $20 \%$ of marriages. You do see occasional cases and usually it happens where the woman provokes the male to attend. She is fed up because he is not interested in sex and very often he is forced to come and sometimes it is an ultimatum situation in which the woman states 'I am going to leave unless ....' I I am quite sure that impotence would seriously disturb a large percentage of marriages, but not always. There are cases in which women are quite glad of it, but I think in the majority of normal marriages it would contribute seriously, particularly in the younger age group.

DR S. Solomons (London): Reference ejaculation without erection. I have worked for some time in VD clinics. It occurs very commonly there, and is usually due to constipation in an abstemious male.

DR COOPER: Thank you very much.

DR S. JACobson (St Francis Hospital): As to the use of sexual perversions. What part do these practices have to play in the treatment of sexual disorders?

DR COOPER: Whatever is mutually acceptable within the privacy of one's own room is to my way of thinking normal. It is all too easy to say these things are perverted. The point is that as long as it is emotionally and mutually acceptable I think it is in order.

DR Chisholm: I would not disagree with that except to say with regard to non-consummation any sexual perversions other than normal intercourse can be a reason why the marriage is not consummated. There may be no motivation if sexual feelings are being expressed in other ways, and there is some reason to suppose this will be a less satisfactory pattern.

DR R. V. BERRY (St Bartholomew's Hospital): What is the duration of non-consummation before seeking treatment, and what factors may cause the patients to seek treatment at the point in time at which they do?

DR CHISHOLM: The interval before seeking help can be a minus quality. Some people can go to organizations while they are engaged before they are married, especially if they know they are going to have trouble. But they may go on complaining, and ask for a physical examination, or ask for birth control advice, etc., when really they have serious doubts whether they are going to be sexually competent. After marriage, the duration of non-consummation can be anything from a few days or weeks to many years, and this is thought to be a prognostic factor. The shorter the duration the easier it is to treat them, and the longer the time before they seek help, or for that matter the more previous treatment they have the more difficult it is to achieve consummation. 
QUESTION: What provokes them to seek treatment, particularly if it is delayed several years?

DR Chisholm: If this is delayed for several years one suspects there are factors in the personality of both spouses and in their mutual interaction which are collusive. If the collusion breaks down, pressure is put on one spouse to go somewhere, as being the one who needs treatment. When we see a spouse who has not presented for many years, it is not uncommon to find that the partner has difficulties also and loses interest after the spouse is treated. It is in my view a joint problem. You may remember that in Friedman's 'Virgin Wives' there was a particularly high percentage of failures in the group coming for treatment 2-5 years after marriage, which he related to the disproportionate number of patients in this group whose primary wish was for a baby.

Dr J. Merry (West Park Hospital): You get a man coming to out-patients who was potent until he was divorced or lost his wife through her death 2-3 years ago, then marries later and finds that with his new partner he is unable to have sexual intercourse. In fact he is impotent. It would seem that for men in middle years they require to make a practice of sexual intercourse in order to maintain their potency. This is a very difficult problem to treat.

DR COOPER: Sex is a habit and the more it is practised the more firmly it becomes established, and in fact most people will say that the best insurance against impotence is regular coitus. I think that the sort of case you have mentioned you have got the problem of a new woman. They are unknown to each other in a personality setting. 2 Basically the treatment is the same, but you may have. to make a bigger investment in the counselling side. Some- $\overrightarrow{\overline{\vec{B}}}$ times if she is a younger woman and she is baffled and bewildered you have to make a bigger impact on the? psychotherapy side. The physical components are the same.

Dr P. Hopkins (Hampstead): I see from the list of $\cong$ participants a number of people from the Tavistock Clinic. I was hoping that someone better qualified than $\vec{O}$ me would take you up on a very important point. In your ${ }^{\circ}$ instructional physical information programme for im- $\vec{\omega}$ potence you quite rightly started by telling us of the $\omega^{\omega}$ enormous incidence of psychogenic factors in these per-7 formances. I must put forward the point that psycho- $\frac{3}{3}$ therapy is the key to treatment of impotence as I treateda number of men with impotence but never had to give $\stackrel{+}{0}$ them instructions on how to perform or give them o education about their anatomy but dealt with their $\omega$ underlying emotional problems. This is often the treat- of ment they need. I am surprised nobody took this point up. $\omega$

DR COOPER: Many treatments work for impotence and 을 there is no one treatment which is better than the other. $\vec{c}$ What is most important is if the patient understands the $\mathbb{D}$ theoretical framework which is in use and believes it. That is important. There are many ways of skinning $a \frac{1}{3}$ cat. I happen to think my way is better. 